\title{
Safety Protocols in Civil and Environmental Engineering Laboratories
}

\section{Dr. Alan S. Hoback, University of Detroit Mercy}

Alan S. Hoback is Professor of Civil \& Environmental Engineering at the University of Detroit Mercy. $\mathrm{He}$ is a registered Professional Engineer in the State of Michigan. Dr. Hoback received his Bachelor's degree in Physics from Hastings College, Nebraska in 1987. He earned his B.S., M.S and Sc.D. from Washington University in 1989, 1991, and 1993, respectively.

\section{Dr. Alexa Rihana Abdallah, University of Detroit Mercy}

Alexa Rihana Abdallah is a Professor in the Civil and Environmental Engineering Department at the University of Detroit Mercy. She earned both her M.S. and Ph.D. in Environmental Engineering from the University of Michigan. 


\title{
Safety Protocols in Civil \& Environmental
}

\author{
Engineering Laboratories
}

\begin{abstract}
Promoting and achieving safety in academic laboratories for students and researchers is every institution's goal. To this end, lab practices are constantly reviewed and revised, and safety policies are generally documented. For this paper, a survey related to lab safety procedures was conducted of civil and environmental engineering department heads, with a $25 \%$ response rate for 56 institutions. The questions asked were related to the process for approving new experiments, whether students were allowed in labs alone, when inspections occurred and how they were performed, and reporting of safety problems. The results demonstrate wide variation in the procedures followed to keep labs safe. At about half the institutions, the faculty member in charge of a lab is solely responsible for determining whether new experiments will be safe, while other institutions follow alternative procedures in which authorities inside and outside the department are consulted. A significant number of department heads surveyed felt that publicity and university or personal priorities could impact approval of new experiments. At $14 \%$ of the institutions, the health and safety officer was involved in approval of new experiments. Graduate students were much more likely to be allowed in labs unsupervised (80\%) than undergraduate students (40\%). Students were granted access to wet/environmental labs with the same frequency as civil labs. Permission to be in the lab was most commonly granted by the faculty member or other departmental authorities. Labs were inspected on average once per year, most commonly by a health and safety officer. Wet/environmental labs were more likely to be inspected by health and safety officers (91\%) than other labs (82\% and 34\%). Reports of unsafe situations were most commonly handled through protocol inside each university's department. Considering the low incident rate reported at academic institutions, the current practices all seem well-warranted, despite the wide variation in the safety protocols followed.
\end{abstract}

\section{Introduction}

Accreditation of civil and environmental engineering programs requires that students conduct experiments in at least two areas [1]. Out of concern for student safety, lab practices are reviewed. For accredited institutions, policies about safety in laboratories are documented in self-study reports to the Engineering Accreditation Commission (EAC) of the Accreditation Board of Engineering and Technology (ABET) [1]. Therefore, all institutions have documented safety policies, but those may not be publicly available.

Students should be trained in how to safely conduct experiments. One method proven to be effective in chemistry curriculum is arranging student lab teams so that each person has a turn investigating and monitoring the safety issues specific to a lab session [2]. Other appropriate practices that include training teaching assistants in safety protocols [3], organizing a lab space with safety in mind [4], or making use of a virtual lab. 
In civil and environmental engineering, there can be many types of lab spaces. It depends on the faculty members' areas of interest and program emphasis. However, various types of labs can be grouped into three major categories based on the particular hazards they contain. In laboratories that involve construction, materials and machinery, students encounter hazardous physical devices. In environmental and biological labs, hazards are more likely to originate from exposure to chemicals or biological agents. However, there are exceptions because in construction labs someone could be exposed to cement dust, and in environmental labs a person might endure physical injury by broken glass or hot plates. Technology and computer labs may simply be a space to do homework assignments or might be related to sensors and data acquisition.

The Bureau of Labor Statistics (BLS) lists injury rates for types of industries in the United States [5]. The rate of nonfatal injury for colleges, universities, and professional schools is 1.8 out of 10,000 workers. This is the lowest rate for any industry listed in the report. Therefore, higher educational institutions are generally safer than most other industries. The data does not differentiate the type of incidents that contribute to the injury rate. A low overall injury rate does not necessarily correlate to the degree of lab safety since some injuries will be unrelated to lab work. Actual injury rate is likely higher than the data shows because it only includes reported injuries above a certain threshold. The BLS tracks causes of days away of work by industry, but it groups education with health services, which is the industry with the highest injury rate. Therefore, no analysis was done on whether the types of injuries at universities could reflect lab accidents.

Generally, city governments are responsible for building and fire safety. Other alternative safety monitors are found at the township, county and state level.

The Occupational Safety and Health Administration (OSHA) is responsible for monitoring working conditions in the United States. OSHA has authority to inspect any place of work at any time, but twenty-six states have approved plans. This means that OSHA has delegated authority to them. OSHA directly runs the program in the other states [6]. OSHA plans inspections using three processes. First, programmed inspections are those that happen frequently because the industry is hazardous. Second, complaint inspections are responses to worker(s) complaining about working conditions. Third, referral inspections are responses to health inspectors referring issues to OSHA. Although inspections are rare at manufacturing establishments, the threat of an inspection and the fallout from a failed inspection factor into the decision to comply with regulations [7].

OSHA data on inspections was accessed for the SIC business classification code 8221 which represents colleges and universities [8]. OSHA lists a total of 7 citations for unsafe conditions from June 2008 to June 2018. This data reflected only three institutions, with 5 of the citations at a single institution from a single inspection. That one cluster of citations was related to improper operations of academic lab equipment but was not related to civil \& environmental engineering programs. The citations at the two other institutions were related to the operation of heavy equipment which is typically done by facilities staff rather than students.

The primary goal of this paper is to inquire about safety protocols at universities with civil \& environmental engineering programs to determine if there is a standard process. If the low 
accident rate in labs is due to the fact that most institutions follow similar processes, then this paper should explore those methods and describes how and why they promote safety.

In addition, training, lab access, inspections, and reporting are all issues faced in industrial settings. The authors wanted to see how educational institutions handled these issues. Also, the authors were dealing with ill-defined institutional approval processes for new experiments so they wanted clarification from other universities about how this is done.

\section{Methods}

This study was conducted through a survey of civil and environmental engineering department heads and distributed by email. The survey was developed based on the goals of the study, with several rounds of review and revision to ensure that the questions would be interpreted as intended.

The study focuses on four issues: approval of new experiments, training of students to be in the labs, inspections of labs for unsafe conditions, and reporting lab accidents and documentation related to laboratory safety. These are all basic but important concerns. They were chosen because they were all questions that any respondent should be able to answer completely.

The list of department heads was provided by ASEE. The email addresses were given for 223 people. A link to an anonymous electronic survey was provided. Of the 56 that replied, two institutions offered bachelor programs only, six offered a masters programs as the top degree, and forty-six offered doctoral degrees. Two respondents left the institution type blank.

Several multiple response questions were asked, such as "Check all authorities that approve new experiments." It was necessary to keep most questions as multiple choice questions so that statistical analysis could be performed despite that limiting the form of a response constrains the answers. A few comments were requested regarding the institution's inspection and complaint response processes. A wide variety of responses was expected, so this portion of the questionnaire could not be put in the multiple choice format.

\section{Results and Discussion}

The questions in the survey were divided into four sections as they related to: new experiments, student safety, lab inspections, and accident reports \& documentation. Additionally, there was a section for optional comments at the end of the survey. All data were interesting, and none were withheld from this paper, except that comments were condensed.

\section{New Experiments: Approval and Refusal}

The results of who is responsible for approving new experiments are shown in Table 1. 
Table 1. Approval of new experiments

\begin{tabular}{|l|l|}
\hline Responsible Person & Percentage \\
\hline Faculty Member & $93 \%$ \\
\hline Lab Manager & $32 \%$ \\
\hline Dept Chair/Director & $20 \%$ \\
\hline Univ Health/safety officer & $14 \%$ \\
\hline Dept Committee & $9 \%$ \\
\hline Dean/Administrator & $7 \%$ \\
\hline College Committee & $4 \%$ \\
\hline University Administrator & $2 \%$ \\
\hline External Entity & $2 \%$ \\
\hline University Committee & $0 \%$ \\
\hline
\end{tabular}

Faculty members were selected by $93 \%$ of respondents. However, this response option is vague. For example, it could mean that they were solely responsible for approving a project proposed by students, or the faculty approval could be one step of a larger process. Faculty members were the only approver indicated by 25 of $56(45 \%)$ institutions. This implies no formal approval process, yet it doesn't rule out that they could be filing decisions with the department. This rate is $42 \%$ for doctoral institutions, and $63 \%$ of master and bachelor institutions. This could indicate that the types of experiments at doctoral institutions are more complicated, but the difference was not statistically significant considering the small sample. When respondents replied that they have multiple approval authorities, it could be implied that each authority independently approves new experiments, or that the responsibility is shared.

Most approval happened inside of the department with the lab manager as the primary approver (32\%), but $25 \%$ required approval outside of the department. The biggest outside approver was a university health and safety officer $(14 \%)$. Master and bachelor programs were significantly less likely to have a lab manager approve new experiments. This could be due to the fact that they are less likely to employ a lab manager.

The survey asked whether publicity or the approver's priorities had influence on whether a new experiment was approved. The approver's priorities were felt to be a factor in the approval by $36 \%$, and $16 \%$ for publicity. These numbers indicate that approving of lab experiments could be affected by reasons outside of safety.

Many factors can result in the refusal to approve new experiments. Priorities can be a major factor for many different reasons. The lab may have limited space or the budget for new equipment or supplies may be limited. Additionally, lab managers may not have time to support all experiments that are proposed.

There were no significant correlations between these non-safety reasons and who approves the experiments. However, the trend closest to significance was that institutions with lab managers may think that the approver's priorities could be a factor in approving a new experiment. This supports the possible interpretations above. 


\section{Student Safety: Supervision and Certification}

One major safety concern is granting students access to labs without supervision. Table 2 summarizes the percentage of undergraduate and graduate students allowed to work unsupervised in different lab environments. The results for grad students filter out institutions without grad programs.

Table 2. Percentage of students working unsupervised

\begin{tabular}{|l|l|l|l|}
\hline Lab & $\begin{array}{l}\text { Undergrad } \\
\text { Students }\end{array}$ & Grad Students & $\begin{array}{l}\text { p-value Undergrad } \\
\text { vs. Grad }\end{array}$ \\
\hline $\begin{array}{l}\text { Wet / } \\
\text { Environmental }\end{array}$ & $48 \%$ & $83 \%$ & 0.0003 \\
\hline $\begin{array}{l}\text { Materials, } \\
\text { Construction, } \\
\text { Machinery }\end{array}$ & $41 \%$ & $85 \%$ & 0.0001 \\
\hline $\begin{array}{l}\text { Technical / } \\
\text { Computer }\end{array}$ & $89 \%$ & $96 \%$ & 0.650 \\
\hline
\end{tabular}

The table shows that graduate students have more privileged lab access than undergraduate students. Except, the statistical test didn't support that grad students had any higher privilege in computer labs.

The physical and environmental labs both allowed much less access for undergraduate students. The materials, construction, and machinery labs had the most restrictive access, but it was roughly the same as environmental lab access. A statistical test shows that there is no support for wet/environmental labs being treated any differently than materials labs for either grad or undergrad students. However, the type of lab with the most lab access was technical / computer. A statistical test which shows greater access to it is supported by $\mathrm{p}<0.0001$ for undergrads, and $\mathrm{p}=0.0165$ for grad students. This result was expected since this type of lab has fewer safety concerns for unsupervised students than others. A few institutions do not allow students in these labs unsupervised, but this may be more to do with having full-time support staff than with safety concerns.

Determining student access to labs and student certification to work unsupervised falls on several individuals. Table 3 shows the results of who determines or certifies whether students can be alone in the labs.

Table 3. Student Certification

\begin{tabular}{|l|l|}
\hline Who certifies student access & Percentage \\
\hline Faculty member & $86 \%$ \\
\hline Lab Manager & $52 \%$ \\
\hline Chair / director & $16 \%$ \\
\hline Department Committee & $7 \%$ \\
\hline
\end{tabular}


Since these results exceed $100 \%$, it appears that duties are shared. It is possible different authorities are approving access to different labs. When lab managers were employed by the institution, they were a party to the approval of student access $83 \%$ of the time.

Granting access to labs requires students and staff to read and follow general safety and emergency guidelines. For environmental/wet labs, $87 \%$ reported that students are required to attend specific safety training on equipment and processes pertaining to the specific laboratory. Students also need to take web-based courses that are offered through the university. For environmental labs, $92 \%$ of the institutions offering graduate degrees have lab managers certify student readiness to work in the lab without supervision. Only $8 \%$ reported that the faculty member is the one responsible for training and certification of students. The two primarily undergraduate institutions indicated that the faculty member trains students interested in pursuing undergraduate research and most often is present to supervise their work in the environmental/wet lab.

Proper handling and disposal of hazardous materials is the responsibility of lab users. However, 91\% of institutions with wet/environmental labs have their environment, health \& safety (EHS) department provide services and collection and oversee and ensure compliance with appropriate regulations. EHS also responds to laboratory spills.

\section{Lab inspections}

The survey asked about the entities responsible for lab inspection and the frequency at which this inspection happens. The results are shown in Table 4.

Table 4. Lab Inspections

\begin{tabular}{|l|l|l|l|}
\hline Lab & ABET & OSHA & $\begin{array}{l}\text { Health \& Safety } \\
\text { Officer }\end{array}$ \\
\hline Wet / Environmental & $39 \%$ & $7 \%$ & $91 \%$ \\
\hline $\begin{array}{l}\text { Materials, } \\
\text { Construction, } \\
\text { Machinery }\end{array}$ & $41 \%$ & $7 \%$ & $82 \%$ \\
\hline $\begin{array}{l}\text { Technical / } \\
\text { Computer }\end{array}$ & $25 \%$ & $2 \%$ & $34 \%$ \\
\hline
\end{tabular}

Only about $40 \%$ of the respondents said ABET had inspected their labs, this is surprising since lab inspection was a major emphasis of ABET site visits for the last several years. During accreditation visits, certainly all ABET evaluators go on tours of labs. However, some of the tours may have been more focused on safety issues, therefore the survey respondents could have subjectively felt that they were more like inspections.

Some institutions have been inspected by OSHA. Some respondents who reported that OSHA had inspected their institution also commented that it had been very infrequent. The differences between the rates of inspections for ABET versus OSHA and internal officers is statistically significant with $\mathrm{p}<0.0001$. 
Inspection of physical labs by university health and safety officers is nearly universal. It was not asked if each institution employed a person in that role. It is possible that some institutions do not have such a person in house and that might affect inspection schedules. The results were higher for wet/environmental labs. A statistical test showed a $\mathrm{p}$ of 0.16 for whether health and safety officers inspected wet/labs more than mechanical labs. A value of 0.16 is not supported at $10 \%$ confidence.

Technical and computer labs are shown to be inspected with less rigor. This reflects the lower level of hazard. Some technical labs may have electrical or other hazards, but computer labs are generally safer. A statistical test shows a p of less than 0.0001 for whether physical labs were more of a concern to health and safety officers than technical labs, so this hypothesis is strongly supported.

The respondents were provided with a chance to comment on the frequency of inspections. The most common response was that their university health and safety officer visited all physical labs yearly. The next most common response was that this occurred every semester. Other institutions were inspected more or less frequently.

A wide variety of comments were provided about lab inspection processes. Some respondents noted that their department had their own health and safety officer. Three institutions noted that the local city departments regularly inspected labs. Some respondents reported that the faculty members were responsible for inspection. This shows that faculty members often have ownership of their labs in many respects such as deciding what experiments are conducted and monitoring safety. Some respondents highlighted the higher safety expectations for biological/environmental labs.

\section{Reporting \& Documentation}

The last part of the survey asked for comments about the process for reporting unsafe situations. The type of unsafe situation can vary dramatically between labs. Environmental labs could have chemical spills, while mechanical labs could have equipment with electrical faults. Yet, the question did not differentiate if there were different types of reporting processes for the types of labs. Many respondents replied reporting was an internal process. Reports were made to the faculty member in-charge of the lab, the lab manager, or the chair person. A few respondents commented that they have a university process for reports, such as contacting the health \& safety officer.

A few respondents provided their institution's safety related documents or links to them. The documents were instructions to students about being safe in the labs. Not enough documents were provided to make further generalizations.

\section{Additional Comments}

Several respondents provided interesting comments. Others provided links to their posted safety methods. Here are some notes on those.

University $\mathrm{C}$ has a warning system. If certain hazardous tests are being performed, a warning light is activated and access is restricted. 
University D has no information on-line. The environmental lab has a Material Data Safety Sheet, personal safety equipment, and general instructions posted on the door. The first session of each related lab course is dedicated to training students in safety protocols. Since it is mostly an undergraduate program, student research activity in the lab is limited, so no formal process is in place to train student researchers in advanced methods.

University $L$ replied with detailed safety instructions, but none were specific to the environmental labs. They were mostly general instructions about keeping labs clean.

University $\mathrm{T}$ has extensive materials posted on their website. They have a chemical hygiene plan for each lab, safety guides for certain pieces of equipment, chemical compatibility charts, checklists for reorganization of the lab spaces, safety sheets for the commonly used materials, and posts lab inspection results on-line.

\section{Conclusion}

Student safety when conducting experiments in labs is the primary concern of this paper. Serious injury seems relatively uncommon for students in civil \& environmental engineering labs. If there were serious injuries, then that would have likely spurred OSHA compliant or referral inspections.

Respondents report a wide variety of processes across institutions. Since the reported incident rate is very low, and no relevant OSHA safety citations have been found, all protocols that the institutions follow appear to be adequate to ensure student safety. Therefore, institutions have found various means of making their labs safe, so flexibility in safety protocols should be promoted. There seems to be no reason to favor one safety process over another, since current practices all seem well warranted and have proven equally safe.

Additional research in this topic could follow in a few paths. First, there were no questions about whether labs were accessible to students with disabilities. Having disabilities might bring in special safety concerns depending on the type of disability. Second, student perspectives regarding lab safety could be reported. Third, a comparison could be made between the opinions of department heads, lab managers, and safety officers. 


\section{References}

[1] Accreditation Board of Engineering and Technology, "Self-Study Templates," 2018. [Online]. Available: http://www.abet.org/accreditation/self-study-templates/. [Accessed June 18, 2018].

[2] P. Alaimo, J. Langenhan, M. Tanner, and S. Ferrenberg, "Safety teams: An approach to engage students in laboratory safety," Journal of Chemical Education, vol. 87(8), pp. 856-861, 2010.

[3] D. Herrington, and M. Nakhleh, "What defines effective chemistry laboratory instruction? Teaching assistant and student perspectives," Journal of Chemical Education, vol. 80(10) pp. 1197, 2003.

[4] M. Jiménez, L. Romero, M. Domínguez, and M. del Mar Espinosa, "5S methodology implementation in the laboratories of an industrial engineering university school," Safety science, vol. 78, pp. 163-172, 2015.

[5] United States. Bureau of Labor Statistics, 2016 Survey of Occupational Injuries \& Illnesses, Charts Package, November 9, 2017. [On-line]. Available: https://www.bls.gov/iif/osch0060.pdf. [Accessed June 18, 2018].

[6] United States. Occupational Safety and Health Administration, "State Plans," 2018. [Online]. Available: https://www.osha.gov/dcsp/osp/. [Accessed June 18, 2018].

[7] J. Mendeloff, and W. Gray, "Inside the black box: How do OSHA inspections lead to reductions in workplace injuries?" Law \& Policy, vol. 27(2), pp. 219-237, 2005.

[8] United States. Occupational Safety and Health Administration, "General Duty Standard, Integrated Management Information System (IMIS),” 2018. [On-line]. Available: https://www.osha.gov/pls/imis/generalsearch.html. [Accessed June 18, 2018]. 